\title{
Inflammatory Status and Glycemic Control Level of Patients with Type 2 Diabetes and Periodontitis: A Randomized Clinical Trial
}

\author{
Biagio Rapone $^{1, *(\mathbb{D})}$, Elisabetta Ferrara ${ }^{2}(\mathbb{D})$, Massimo Corsalini ${ }^{3}\left(\mathbb{D}\right.$, Erda Qorri ${ }^{4}\left(\mathbb{D}\right.$, Ilaria Converti ${ }^{5}$, \\ Felice Lorusso ${ }^{6}\left(\mathbb{D}\right.$, Maurizio Delvecchio ${ }^{7}(\mathbb{D})$, Antonio Gnoni ${ }^{1}$, Salvatore Scacco ${ }^{1}$ (D) and Antonio Scarano ${ }^{6}$ (D)
}

1 Department of Basic Medical Sciences, Neurosciences and Sense Organs, "Aldo Moro" University of Bari, 70121 Bari, Italy; gnoniantonio@gmail.com (A.G.); salvatore.scacco@uniba.it (S.S.)

2 Complex Operative Unit of Odontostomatology, Hospital S.S. Annunziata, 66100 Chieti, Italy; igieneeprevenzione@gmail.com

3 Interdisciplinary Department of Medicine, University of Bari, 70121 Bari, Italy; massimo.corsalini@uniba.it

4 Dean Faculty of Medical Sciences, Albanian University, Bulevardi Zogu I, 1001 Tirana, Albania; erda79@yahoo.com

5 Department of Emergency and Organ Transplantation, Division of Plastic and Reconstructive Surgery, "Aldo Moro" University of Bari, 70121 Bari, Italy; ilaria.converti@gmail.com

6 Department of Oral Science, Nano and Biotechnology and CeSi-Met University of Chieti-Pescara, 66100 Chieti, Italy; drlorussofelice@gmail.com (F.L.); ascarano@unich.it (A.S.)

7 Department of Metabolic and Genetic Diseases, Giovanni XXIII Children's Hospital, 70126 Bari, Italy; mdelvecchio75@gmail.com

* Correspondence: biagiorapone79@gmail.com; Tel.: +39-3477619817

Citation: Rapone, B.; Ferrara, E.; Corsalini, M.; Qorri, E.; Converti, I.; Lorusso, F.; Delvecchio, M.; Gnoni, A.; Scacco, S.; Scarano, A. Inflammatory Status and Glycemic Control Level of Patients with Type 2 Diabetes and Periodontitis: A Randomized Clinical Trial. Int. J. Environ. Res. Public Health 2021, 18, 3018. https://doi.org/ 10.3390/ijerph18063018

Received: 19 February 2021

Accepted: 12 March 2021

Published: 15 March 2021

Publisher's Note: MDPI stays neutral with regard to jurisdictional claims in published maps and institutional affiliations.

Copyright: (c) 2021 by the authors. Licensee MDPI, Basel, Switzerland. This article is an open access article distributed under the terms and conditions of the Creative Commons Attribution (CC BY) license (https:/ / creativecommons.org/licenses/by/ $4.0 /)$.
Abstract: Background: Based on the holistic approach to prevention diabetic disease, the role of periodontal inflammation in type 2 diabetes mellitus (T2DM) is under intensive scrutiny. Data from clinical trials have shown benefit from a periodontal therapy in providing patients with type 2 diabetes improvement despite relatively disappointing long-terms response rates. The aim of this study was to investigate the short-term glycemic control level and systemic inflammatory status after periodontal therapy. Methods: This was a randomized trial with a 6-months follow-up. Participants aged $56.4 \pm 7.9$ years with diagnosed type 2 diabetes and periodontitis were enrolled. Among the 187 type 2 diabetic patients, 93 were randomly assigned to receive non-surgical periodontal treatment immediately and 94 to receive the delayed treatment. Within and between groups comparison was done during the study period, and the differences between groups were assessed. Results: The difference between $\mathrm{HbA1}$ c values at baseline $(M d n=7.7)$ and 6 months after non-surgical periodontal treatment $(M d n=7.2)$ was statistically significant, $U=3174.5, p=0.012, r=0.187$. However, although technically a positive correlation, the relationship between the glycated hemoglobin value and periodontal variables was weak. The differences between both the groups over 6 months were not statistically considerable, failing to reach statistical significance. At 6 months the difference between groups about the C-reactive protein (CRP) levels was statistically significant, $U=1839.5, p=0$, $r=0.472$, with a lower concentration for the intervention group. Furthermore, the intervention group showed a statistically significant difference between baseline and 6 months evaluation $(U=2606.5$, $p=0, r=0.308$ ). Conclusions: The periodontal intervention potentially may allow individuals with type 2 diabetes to improve glycemic control and CRP concentrations, and diabetes alters the periodontal status.

Keywords: type 2 diabetes; periodontitis; periodontal inflammation; systemic inflammation; Creactive protein; non-surgical periodontal treatment; dental public health

\section{Introduction}

Despite advances in prevention and treatment measures, diabetes mellitus remains one of the most important chronic diseases worldwide, associated with high mortality and 
morbidity, with an estimated 300 million cases in the year 2025 [1]. Research has pointed to the multiplicative effect when several risk factors are present and, of interest, scientific evidence underlines the possibility of closely linked inflammatory etiology. Accumulating evidence supports a key role of periodontal inflammation in the pathophysiology of several systemic disorders [2-4]. Progress in understanding the pathogenesis of diabetes has generated increasing interest in targeting inflammatory pathways and biomarkers of inflammation to help prevent and control diabetes and related sequelae [5-8]. Periodontitis is a chronic multifactorial inflammatory disease affecting the tissues surrounding the teeth [7], and has a prevalence estimated at $20-50 \%$ of the global population. Commonly, over $10 \%$ of the older population has severe disease [8-10]. Periodontitis can promote systemic chronic inflammation (SCI) that can, in turn, lead to exacerbation of type 2 diabetes [9-11]. This consistent clinical evidence for an interconnection between periodontitis and diabetes risk comes from multiple randomized controlled trials (RCTs) and epidemiological investigations data that have proven that periodontal treatment resulted in $\mathrm{HbA} 1 \mathrm{c}$ levels reduction $[10,12,13]$. All these findings are in harmony with the hypothesis that periodontitis and diabetes may fuel each other in a bidirectional pathway [9,13], in which a reciprocal action of inflammatory mediators leads to worsen of pathological conditions, becoming closely linked diseases [11].

The metabolic dysregulation in diabetes associated with hyperglycemia and hyperinsulinemia are predisposing factors to infectious diseases in diabetes. Periodontitis is one of the most common complications of diabetes mellitus, affecting more than $50 \%$ of the diabetic population [14]. Periodontitis has been implicated in an increased risk of type 2 diabetes, and diabetes patients are two to five times as likely to develop risk of suffering periodontitis compared to healthy individuals, but the molecular mechanisms linking these two diseases are partially known [5,15-19]. Mechanistic studies in in vivo conditions agree to assert that among regulatory factors of this connection should be explored [20]. Specifically, the pathway model that aggregates the knowledge about the impact of diabetes on periodontal status have been well-documented and characterized [14]. Data on the clinical impact of diabetes on periodontal inflammation enhancement come from two sources: the potential direct effect of hyperglycemic status, which may be responsible for the oral microbiome shifting, impaired cellular function and host defense, and upregulation of the circulant proinflammatory mediators known to be released primarily by immune cells [21-27]; the accelerated glycation of protein and lipids mediated by Advanced glycation end products (AGES) and fatty acids, which may indirectly contribute to the degenerative process of periodontal tissues and influence negatively osteogenesis [28-33]. In contrast, it has been assumed that long term low-level exposure to periodontal inflammation have a negative impact on metabolic control, but the pathway by which periodontitis contributes to worsening diabetes is still unclear [16]. Human studies have demonstrated that patients suffering from periodontitis exhibit higher concentrations of proinflammatory cytokines, such as tumor necrosis factor-alpha (TNF- $\alpha$ ), C-reactive protein (CRP), interleukin-6 (IL-6) and Il- $1 \beta$. Several mechanisms of altered macrophage polarization during obesity have been recently suggested. Based on this evidence, dysregulation in the cytokine network may contribute to development or sustaining diabetes via activation of the chronic systemic inflammation [14-16,21]. The clinical relevance of increases of CRP in subjects with periodontitis has been demonstrated by showing that the peripheral inflammatory response is reflected in increased concentrations of the C-reactive protein in patients with periodontal infections compared to periodontally health individuals. The most reliable evidence for the co-occurrence of diabetes and periodontitis and the correlation between the two diseases is a function of inflammatory pathway $[2,5,13,30]$.

Based on the simultaneous occurrence of periodontitis and diabetes, as recorded in most of clinical trials, this paper briefly resumes the conceptual cycle that accounts for the theory of bidirectional relationship between diabetes and periodontitis and explores the impact of suppression of periodontal inflammatory response pathway in minimizing the interrelation between the peripheral and systemic inflammatory status. In this perspective, 
the chief object of this trial was aimed to investigate the effectiveness of non-surgical periodontal treatment on glycemic control in patients diagnosed type 2 diabetes and, simultaneously, the potential improvement of systemic inflammatory status.

\section{Materials and Methods}

\subsection{Study Design and Participants}

The study was a single center double-blind with two parallel-groups, randomized controlled trial with a follow-up of 6 months. The trial was conducted in compliance with the provisions of the Declaration of Helsinki and Good Clinical Practice guidelines. The study was reviewed and received ethical approval from the Institutional Review Board of Albanian University, Number 385. Patients were recruited between June 2018 and January 2020 and included if diagnosed with type 2 diabetes and if their diabetes therapy had remained unchanged over the previous 3 months and they had not participated in DM educational programs prior to the commencement of study. Further, to be included, patients were required to have a diagnosis of periodontitis [20].

\subsection{Recruitment, Randomization and Blinding Status}

Potentially eligible patients were recruited based on medical record data. Patients with a diagnosis of type 2 diabetes, within the previous 3 years, and having diagnosis of periodontitis [23]. Diagnostic criteria of periodontitis have been validated since 1999 [27] by the American Academy of Periodontology (AAP) and have been enlarged in the 2017 revision [28]. According to the American Academy of Periodontology (AAP), clinical diagnosis of periodontitis was made if clinical attachment loss (CAL) affected $\geq 2$ nonadjacent teeth or buccal/oral CAL of $\geq 3 \mathrm{~mm}$ with pocketing of $>3 \mathrm{~mm}$ was detectable at $\geq 2$ teeth, and the detected CAL cannot be attributed to traumatic causes, dental caries, endodontic lesion or molar malpositions. Patients were excluded if they: had insulin dependent diabetes mellitus, or higher chronic disease, smoking or consuming alcohol, had used any antibiotics or long-term anti-inflammatory drugs in the last 6 months prior to the trial; females who are pregnant, lactating or less than 6 weeks post-partum; having received periodontal treatment within the previous year, were unable to provide informed consent or comply with study requirements at the time of the recruitment encounter and were younger than 18 years. After the trial eligibility criteria were confirmed, each patient provided informed consent, which was mandatory before randomization. Randomization was done using a computer-generated series of numbers that ensured balance between experimental groups. Prior to conducting the research study, sample size was determined, setting Type I error $(\alpha)$ at 0.05 and Type II error $(\beta)$ at 0.02 and power at $80 \%$. Participants were randomly assigned, in a 1:1 ratio, to receive either the non-surgical periodontal treatment (intervention group-IG) or delayed non-surgical periodontal treatment (control group - CG). Due to the nature of the intervention neither participants were masked to allocation, while the trial statistician and one clinical trial personnel were blinded to the study groups during data analysis. The design and methods of this RCT were in accordance with the recently published extension of the CONSORT statement to randomized trials of non-pharmacological treatment. Figure 1 illustrates the design of the study in the form of a CONSORT diagram. 
Flow Diagram

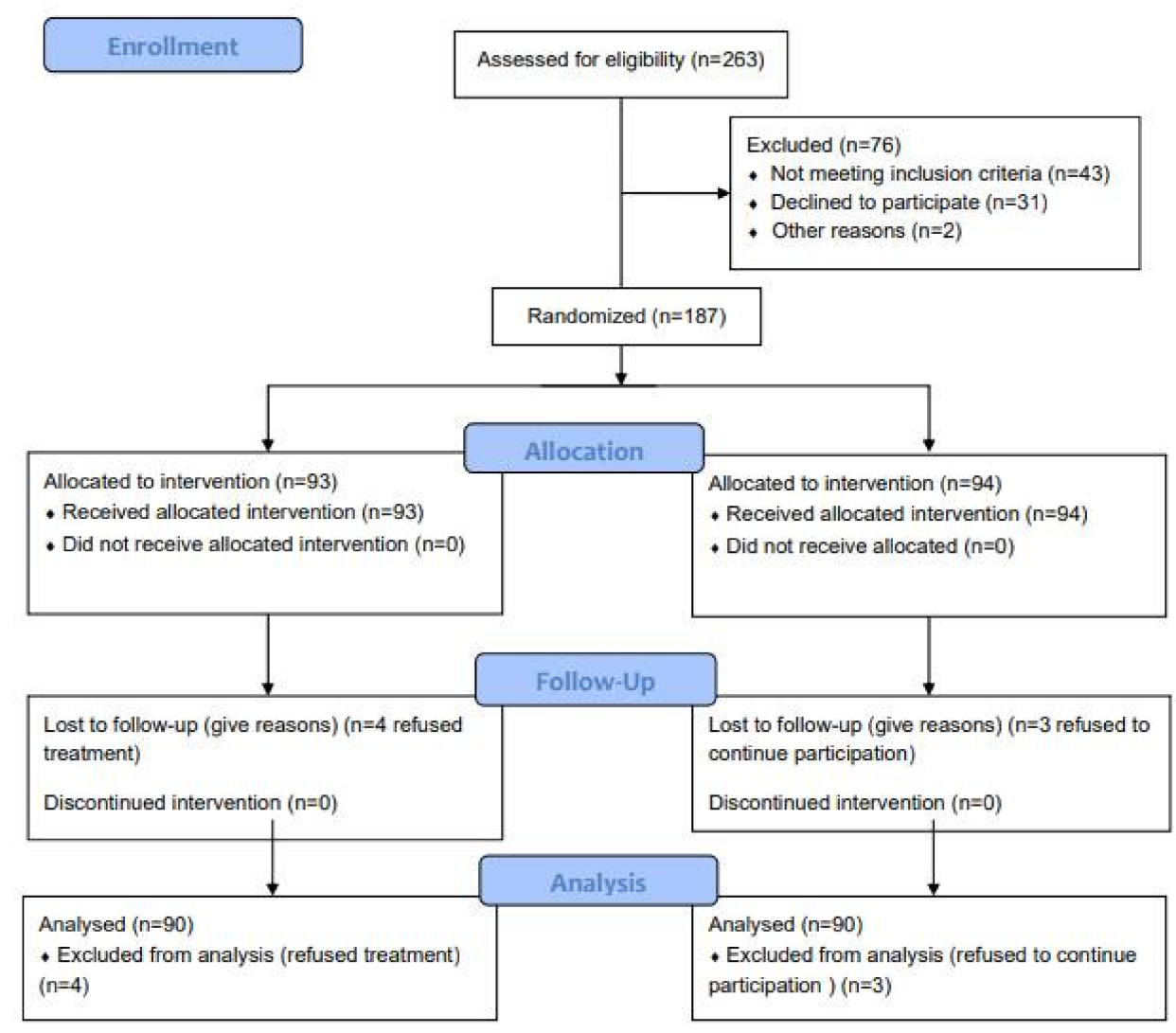

Figure 1. CONSORT flow chart. This figure shows the flow of patients through the trial according to the criteria recommended in the CONSORT guidelines.

\subsection{Assessment of Clinical Periodontal Parameters}

At baseline and at 3 and 6 months after non-surgical periodontal treatment, the following clinical parameters were detected to record gingival and periodontal status by a single examiner using a standardized manual periodontal probe (CP11 Hu Friedy, Europe) in six sites of each tooth (distobuccal surface, centre of vestibular surface, mesiobuccal surface, distolingual surface, centre of lingual surface and mesiolingual surface): pocket depth (PD) [1], to assess the periodontal status by measuring the space between the pathologically detached gingiva and the tooth; clinical attachment level (CAL), to assess the periodontal status by measuring the distance from the cemento-enamel junction of the tooth to the pocket base; gingival index (GI-Löe19), to assess the severity of gingival inflammation on the basis of chromatic evaluation, consistency and bleeding on probing; plaque index (PI-Silness and Löe), to assess the thickness of bacterial plaque at the cervical margin of the teeth. In order to reduce the effects of the examination variability, the technique proposed by Silness and Löe was used on determining the PI score [2], mesial (M) and distal (D) measurements. Glycated hemoglobin (HbA1c) and CRP were measured at baseline and during the third and sixth month of follow-up at a local diabetic center.

\subsection{Non-Surgical Periodontal Treatment}

The practical application of periodontal treatment is the result of the ambivalence of periodontal disease, consisting of biologic etiological components and a psychological issue stood regarding the perception of individuals need to address the pathological condition. Then, the earliest stage of periodontal treatment for the case group consisted of motivational intervention helping patients change behavior associated with customized 
oral hygiene instructions for daily plaque control, pointed out on the potential successful outcomes, including the improvement of periodontal disease and potential benefit for diabetes control. At the end of the first phase, active professional treatment was carried out. Scaling and root planing were performed under local anesthesia and treatment was divided in four sessions within $24 \mathrm{~h}$, each of $45 \mathrm{~min}$ for quadrant and were performed using an ultrasonic scaler (PIEZO-soft ultrasonic scaler; KaVo Dental, Germany) equipped with PIEZO Scaler Tip 201, and manual instruments (Gracey Curettes, SG 1/2, 3/4, 5/6, 7/8, 11/12, 13/14; Gracey Curette, SAS 3/4, 11/12, 13/14; Hu-Friedy, USA). The ultrasonic instrumentation was performed in apical to cervical direction using linear oscillations and at $30 \mathrm{KHz}$ with a medium power setting [3]. A continuous water spray on the working area was maintained, and a subgingival irrigation with an antiseptic mouthwash (chlorhexidine $0.12 \%$ ) was associated. All patients were treated by the same operators using the standard curettes angle and force applications. At the end of the 6-month follow-up period the non-surgical periodontal treatment was carried out for the control group, performing the same procedures for an ethical reason.

\subsection{Study Outcomes}

The primary outcome of the clinical trial was the change from baseline to 6 months endpoint in glycosylated hemoglobin (HbA1c) (time frame: baseline, 3 months, 6 months). The secondary outcomes were the change of periodontal measurements. Degree was categorized, based on primary criteria and the presence of risk factors as Grade A, characterized by a slow rate of progression; Grade B, characterized by a moderate rate of progression and Grade $\mathrm{C}$, characterized by a rapid rate of progression. Severity was determined based on CAL, and categorized as: Stage I: periodontitis, with a mean of $1 \mathrm{~mm}$ of periodontal attachment loss; Stage II: moderate periodontitis, with a mean of $3 \mathrm{~mm}$ of periodontal attachment loss; Stage III: severe periodontitis, with $\geq 5 \mathrm{~mm}$ of periodontal attachment loss, and teeth loss $\leq 4$ and Stage IV: advanced periodontitis, with $\geq 5 \mathrm{~mm}$ of periodontal attachment loss teeth loss $\geq 5$.

\subsection{Governance and Ethics}

The study was approved by the local Ethics Committee of Albania University, Tiran, Albania (Nr. 385 Prot.). The study was conducted according to the guidelines of the Declaration of Helsinki. Informed consent was obtained from all subjects involved in the study.

\subsection{Statistics}

Statistical analyses were conducted by using SPSS software (Statistical Package for the Social Sciences, version 14.0, SPSS Inc., Chicago, IL, USA). The alpha level was set at $5 \%$. Normality was verified by applying the Shapiro-Wilk test. Examined variables did not present normal distribution, and consequently, a non-parametric approach was used. Additionally, box plots were visually scrutinized, and descriptive analysis, skewness and kurtosis were used to evaluate deviation from normality. A $p$-value of $>0.05$ indicated a normal distribution. To compare the variables within- and between-groups, the MannWhitney test was applied at each time-point. Correlation was analyzed using Spearman's correlation coefficient. Multiple linear regression analysis was performed to assess relative association between $\mathrm{HbA} 1 \mathrm{C}$ and periodontal parameters assuming $\mathrm{HbA1C}$ the dependent variable and periodontal indices the independent variables.

Our sample size calculation was determined to detect a difference in change in the primary outcome, $\mathrm{HbA} 1 \mathrm{c}$ of $0.5 \%$ between groups from baseline. Based on the assumption of a standard deviation of $2 \mathrm{mmol} / \mathrm{mol}(0.1 \%)$ with a $5 \%$ significance level using a twosided two-sample z-test, and a drop-out rate of $20 \%$, minimum of 68 participants per group would give us $80 \%$ to detect a difference in $\mathrm{HbA1C}$ of $5 \mathrm{mmol} / \mathrm{mol}(0.5 \%)$ between the two study groups. Participants' characteristics were described with mean and standard deviations for normally distributed data. Data with a skewed distribution are presented as 
medians with an interquartile range. Statistical significance was inferred at a two-tailed $p$ value of $<0.05$.

\section{Results}

A total of 265 subjects were screened, and 187 subjects were randomized into the study. The population consisted of 81 male (45\%) and 106 females (56\%) in total, with a mean age of $56.4 \pm 7.9$. As shown in Figure 1, the 6-month trial was completed by 90 of the 187 participants (48\%) in the intervention group (IG) (four refused treatment) and by 90 of the participants $(48 \%)$ in the control group (CG) (three refused to continue participation).

Table 1 shows the baseline participants characteristics.

Table 1. Participants' characteristics.

\begin{tabular}{ccc}
\hline Characteristics & Intervention Group & Control Group \\
\hline Sex $(N)$ & & \\
\hline Female & 50 & 54 \\
Male & 40 & 36 \\
\hline Age $(\mathbf{y})$ mean \pm SD & $53.2 \pm 11.2$ & $56 . \pm 6.9$ \\
\hline Average $^{*}$ BMI $\left(\mathbf{k g} / \mathbf{m}^{\mathbf{2}}\right.$, mean \pm SD) & $27.8 \pm 6.3$ & $22.3 \pm 5.1$ \\
\hline
\end{tabular}

* BMI: Body Mass Index.

The descriptive analysis of clinical parameters of both groups at baseline is reported in Table 2.

Table 2. Descriptive analysis of clinical parameters at baseline of both groups.

\begin{tabular}{|c|c|c|c|c|c|c|c|c|c|c|c|c|c|c|c|c|c|c|}
\hline & $\begin{array}{l}\mathrm{HbA1}_{\mathrm{c}} \\
(\%) \\
{ }^{*} \mathrm{IG}\end{array}$ & $\begin{array}{l}\text { HbA1 }_{\mathbf{c}} \\
(\%) \\
* \text { CG }\end{array}$ & $\begin{array}{c}p \\
\text { Value }\end{array}$ & $\underset{\text { IG }}{\mathrm{CRP}}$ & $\begin{array}{c}\mathrm{CRP} \\
\mathrm{mg} / \mathrm{L} \\
\mathrm{CG}\end{array}$ & $\begin{array}{c}p \\
\text { Value }\end{array}$ & $\underset{\text { IG }}{\text { PI }}$ & $\begin{array}{c}\text { PI } \\
(\mathrm{mm}) \\
\mathrm{CG}\end{array}$ & $\begin{array}{c}p \\
\text { Value }\end{array}$ & $\begin{array}{l}\text { GI } \\
(\%) \\
\text { IG }\end{array}$ & $\begin{array}{l}\text { GI } \\
(\%) \\
\text { CG }\end{array}$ & $\begin{array}{c}p \\
\text { Value }\end{array}$ & $\underset{\text { (mm) }}{\text { PD }}$ & $\underset{(\mathrm{mm})}{\mathrm{PD}}$ & $\begin{array}{c}p \\
\text { Value }\end{array}$ & $\begin{array}{c}\text { CAL } \\
\text { (mm) } \\
\text { CG }\end{array}$ & $\begin{array}{c}\text { CAL } \\
\text { (mm) } \\
\text { IG }\end{array}$ & $\begin{array}{c}p \\
\text { Value }\end{array}$ \\
\hline Mean & 8.081 & 8.767 & 0.048 & 2.514 & 2.302 & 0.431 & 80.8 & 69.067 & 0.011 & 68.744 & 62.244 & 0.74 & 4.851 & 4.572 & 0.037 & 4.883 & 5.178 & 0.039 \\
\hline Median & 7.7 & 7.5 & - & 2.3 & 2.145 & - & 80.5 & 70.5 & - & 67 & 65 & - & 4.85 & 4.5 & - & 4.8 & 5.3 & - \\
\hline $\begin{array}{l}\text { Std. De- } \\
\text { viation }\end{array}$ & 1.965 & 8.514 & - & 1.173 & 1.221 & - & 16.348 & 19.886 & - & 18.757 & 21.439 & - & 0.568 & 0.482 & - & 0.513 & 0.339 & - \\
\hline Variance & 3.861 & 72.484 & - & 1.375 & 1.492 & - & 267.26 & 395.456 & - & 351.83 & 459.647 & - & 0.323 & 0.233 & - & 0.263 & 0.115 & - \\
\hline Minimum & 5.5 & 5.5 & - & 0.26 & 0.26 & - & 45 & 21 & - & 29 & 18 & - & 4 & 3.3 & - & 3.82 & 4.5 & - \\
\hline Maximum & 17 & 88 & - & 5.43 & 5.11 & - & 100 & 100 & - & 100 & 100 & - & 8 & 5.8 & - & 6.5 & 5.9 & - \\
\hline IQR & 1.375 & 1.525 & - & 1.405 & 1.91 & - & 33 & 32.2 & & 29.5 & $31 . .2$ & - & 0.7 & 0.8 & - & 0.5 & 0.7 & - \\
\hline Skew & 2.592 & 9.258 & - & 0.215 & 0.513 & - & -0.314 & -0.2 & - & -0.046 & 0.108 & - & 1.831 & 0.269 & - & 0.107 & -0.162 & - \\
\hline Kurtosis & 8.741 & 87.062 & - & -0.213 & -0.702 & - & -1.166 & -0.712 & - & -0.946 & -0.783 & - & 9.267 & -0.392 & - & 0.082 & -0.784 & - \\
\hline
\end{tabular}

*IG: Intervention Group; **CG: Control Group; Hb: Hemoglobin; CRP: C-reactive protein; PD: Pocket Depth; CAL: Clinical Attachment Level; BOP: Bleeding on Probing; GI: Gingival Index; PI: Plaque Index; IQR: Interquartile range $p<0.05$.

\subsection{Correlation Analysis between the Variables of Intervention Group at Baseline}

A Spearman rank correlation was performed to test if there was a relationship between the $\mathrm{HbA1c}$ level and periodontal parameters. At baseline, results indicated that there was no significant association between $\mathrm{HbA} 1 \mathrm{c}$ and PI, $r(88)=0.106, p=0.322$, and for GI: $r(88)=0.126, p=0.237$. As shown in Table 3 , no significant association between $\mathrm{HbA} 1 \mathrm{c}$ and PD was found, $r(88)=-0.136, p=0.201$ and no statistically significant association was revealed between $\mathrm{HbA1}$ c and CAL: $r(88)=-0.142, p=0.181$. A significant positive association between PD and CAL in the intervention group, $r(88)=0.718, p=0$ was found. The results of the Spearman rank correlation indicated that there was a positive association between the CRP value and $\mathrm{HbA} 1 \mathrm{c}$ and periodontal parameters, but no significant association was revealed (PI, $r(56)=-0.224, p=0.091$; GI, $r(56)=-0.205, p=0.123$; PD, $r(56)=-0.224, p=0.091$; CAL, $r(56)=-0.01, p=0.938$; HbA1c $r(56)=-0.222, p=0.093)$. 
Table 3. Correlation and significance analysis between all the variables of the intervention group at baseline.

\begin{tabular}{cccccccc}
\hline Baseline & & HbA1c & PI & GI & PD & CAL & CRP \\
\hline \multirow{2}{*}{ HbA1c } & Spearman correlation & 1 & 0.106 & 0.126 & -0.136 & -0.142 & -0.222 \\
\cline { 2 - 8 } & $p$-value (2-tailed) & & 0.322 & 0.237 & 0.201 & 0.181 & 0.093 \\
\hline \multirow{2}{*}{ PI } & Spearman correlation & 0.106 & 0.09 & 0.123 & 0.091 & 0.938 & 0.224 \\
\cline { 2 - 8 } & $p$-value (2-tailed) & 0.322 & & 0 & 0.094 & 0.232 & 0.091 \\
\hline \multirow{2}{*}{ GI } & Spearman correlation & 0.126 & 0.914 & 1 & 0.12 & 0.112 & -0.205 \\
\cline { 2 - 8 } & $p$-value (2-tailed) & 0.237 & 0 & & 0.259 & 0.293 & 0.123 \\
\hline \multirow{2}{*}{ PD } & Spearman correlation & -0.136 & 0.177 & 0.12 & 1 & 0.718 & -0.224 \\
\cline { 2 - 8 } & $p$-value (2-tailed) & 0.201 & 0.094 & 0.259 & & 0 & 0.123 \\
\hline \multirow{2}{*}{ CAL } & Spearman correlation & -0.142 & 0.127 & 0.112 & 0.718 & 1 & -0.01 \\
\cline { 2 - 8 } & $p$-value (2-tailed) & 0.181 & 0.232 & 0.293 & 0 & & 0.938 \\
\hline CRP & Spearman correlation & -0.222 & -0.224 & -0.205 & -0.224 & -0.01 & 1 \\
\hline \multirow{2}{*}{ C.value (2-tailed) } & 0.093 & 0.091 & 0.123 & 0.091 & 0.938 & 0 \\
\hline
\end{tabular}

At 3 months (Table 4), no significant association between $\mathrm{HbA} 1 \mathrm{c}$ and GI was found, with $r(88)=-0.037, p=0.728$; no significant association between $\mathrm{HbA} 1 \mathrm{c}$ and PI, $r(88)=-0.033, p=0.757 ; \mathrm{HbA} 1 \mathrm{c}$ and PD, $r(88)=0.045, p=0.677$; HbA1c and CAL, $r(88)=-0.057, p=0.59$ was revealed. There was a significant positive association between GI and PI, $r(88)=0.943, p=0$. There was no significant association between GI and PD, $r(88)=0.095, p=0.372$; GI and CAL $r(88)=-0.037, p=0.727$; PI and PD, $r(88)=0.101$, $p=0.342$; PI and CAL, $r(88)=-0.008, p=0.942$, and between PD and CAL, $r(88)=-0.009$, $p=0.932$. At 6 months, the results of the Spearman rang correlation indicated that there was no significant association between $\mathrm{HbA1c}$ and periodontal indices. No statistically significant correlation between CRP and all the variables was found.

Table 4. Correlation and significance analysis between all variables of the intervention group at 3 months.

\begin{tabular}{cccccccc}
\hline 3 Months & & HbA1c & GI & PI & PD & CAL & CRP \\
\hline \multirow{2}{*}{ HbA1c } & Spearman correlation & 1 & -0.037 & -0.033 & 0.045 & -0.057 & -0.027 \\
\cline { 2 - 8 } & p-value (2-tailed) & & 0.728 & 0.757 & 0.677 & 0.59 & 0.799 \\
\hline \multirow{2}{*}{ GI } & Spearman correlation & -0.037 & 1 & 0.943 & 0.095 & -0.037 & 0.131 \\
\cline { 2 - 8 } & p-value (2-tailed) & 0.728 & & 0 & 0.372 & 0.727 & 0.217 \\
\hline \multirow{2}{*}{ PI } & Spearman correlation & -0.033 & 0.943 & 1 & 0.101 & -0.008 & 0.127 \\
\cline { 2 - 8 } & p-value (2-tailed) & 0.757 & 0 & & 0.342 & 0.942 & 0.233 \\
\hline \multirow{2}{*}{ PD } & Spearman correlation & 0.045 & 0.095 & 0.101 & 1 & -0.009 & -0.067 \\
\cline { 2 - 8 } & p-value (2-tailed) & 0.677 & 0.372 & 0.342 & & 0.932 & 0.53 \\
\hline \multirow{2}{*}{ CAL } & Spearman correlation & -0.057 & -0.037 & -0.008 & -0.009 & 1 & 0.103 \\
\cline { 2 - 8 } & p-value (2-tailed) & 0.59 & 0.727 & 0.942 & 0.932 & & 0.335 \\
\hline \multirow{2}{*}{ CRP } & Spearman correlation & -0.027 & 0.131 & 0.127 & -0.067 & 0.103 & 1 \\
\hline & p-value (2-tailed) & 0.799 & 0.217 & 0.233 & 0.53 & 0.335 & \\
\hline
\end{tabular}

A statistically significant positive association was found only between PI and GI, $r(88)=0.76, p=0$, and GI and CAL, $r(88)=0.235, p=0.025$ (Table 5). 
Table 5. Correlation and significance analysis between the $\mathrm{HbA} 1 \mathrm{c}$ level and periodontal parameters of the intervention group at 6 months.

\begin{tabular}{cccccccc}
\hline 6 months & & HbA1c & PI & GI & PD & CAL & CRP \\
\hline \multirow{2}{*}{ HbA1c } & Spearman correlation & 1 & -0.032 & 0.058 & -0.03 & -0.034 & 0.046 \\
\cline { 2 - 8 } & $p$-value (2-tailed) & & 0.767 & 0.587 & 0.779 & 0.753 & 0.669 \\
\hline \multirow{2}{*}{ PI } & Spearman correlation & -0.032 & 1 & 0.76 & 0.095 & 0.168 & 0.11 \\
\cline { 2 - 8 } & $p$-value (2-tailed) & 0.767 & & 0 & 0.375 & 0.113 & 0.301 \\
\hline \multirow{2}{*}{ GI } & Spearman correlation & 0.058 & 0.76 & 1 & -0.053 & 0.235 & 0.118 \\
\cline { 2 - 8 } & $p$-value (2-tailed) & 0.587 & 0 & & 0.62 & 0.025 & 0.268 \\
\hline \multirow{2}{*}{ PD } & Spearman correlation & -0.03 & 0.095 & -0.053 & -0.152 & -0.152 & -0.05 \\
\cline { 2 - 8 } & $p$-value (2-tailed) & 0.779 & 0.375 & 0.62 & -0.152 & 0.153 & 0.639 \\
\hline \multirow{2}{*}{ CAL } & Spearman correlation & -0.034 & 0.168 & 0.235 & -0.152 & 1 & 0.091 \\
\cline { 2 - 8 } & $p$-value (2-tailed) & 0.753 & 0.113 & 0.025 & 0.153 & & 0.396 \\
\hline \multirow{2}{*}{ CRP } & Spearman correlation & 0.046 & 0.11 & 0.118 & -0.05 & 0.091 & 1 \\
\hline \multirow{2}{*}{ p-value (2-tailed) } & 0.669 & 0.301 & 0.268 & 0.639 & 0.396 & \\
\hline
\end{tabular}

\subsection{Comparison of Each Parameter between Groups at Baseline, 3 and 6 Months}

As shown in Table 6, at baseline, the intervention group had higher values of $\mathrm{HbA1c}$ $(M d n=7.7)$ as the control group $(M d n=7.5)$.

Table 6. Comparison between groups at each time point.

\begin{tabular}{|c|c|c|c|c|c|}
\hline Indices & Mann-Whitney U & W of Wilcoxon & $\mathbf{Z}$ & $\begin{array}{c}\text { Asymptotic } \\
\text { Significance } \\
\text { (2-tailed) }\end{array}$ & $\begin{array}{c}\text { Exact } \\
\text { Significance } \\
\text { (2-tailed) }\end{array}$ \\
\hline \multicolumn{6}{|l|}{ HbA1c } \\
\hline Baseline & 3.93 & 1.56 & -0.33 & 0.73 & 0.73 \\
\hline 3 months & 3.08 & 2.26 & -2.77 & 0.006 & 0.006 \\
\hline 6 months & 3.75 & 1.49 & -0.83 & 0.4 & 0.4 \\
\hline \multicolumn{6}{|l|}{ PI } \\
\hline Baseline & 2.64 & 2.46 & -4.04 & 0 & 0 \\
\hline 3 months & 57.5 & 3.00 & -11.4 & 0 & 0 \\
\hline 6 months & 15 & 0 & -11.5 & 0 & 0 \\
\hline \multicolumn{6}{|l|}{ GI } \\
\hline Baseline & 3.33 & 2.44 & -2.06 & 0.039 & 0.04 \\
\hline 3 months & 70 & 12.0 & -11.39 & 0 & 0 \\
\hline 6 months & 33 & 1.00 & 11.49 & 0 & 0 \\
\hline \multicolumn{6}{|l|}{ PD } \\
\hline Baseline & 2.88 & 2.15 & -3.3 & 0.001 & 0.001 \\
\hline 3 months & 42.5 & 0 & -11.4 & 0 & 0 \\
\hline 6 months & 2 & 0 & -11.5 & 0 & 0 \\
\hline \multicolumn{6}{|l|}{ CAL } \\
\hline Baseline & 2.62 & 2.32 & -4.08 & 0 & 0 \\
\hline 3 months & 1.30 & 6.25 & -7.85 & 0 & 0 \\
\hline 6 months & 9.48 & 2.84 & -8.8 & 0 & 0 \\
\hline \multicolumn{6}{|l|}{ CRP } \\
\hline Baseline & 3.62 & 4.48 & 1.22 & 0.222 & 0.221 \\
\hline 3 months & 2.62 & 2.12 & -4.07 & 0 & 0 \\
\hline 6 months & 1.83 & 1.83 & -6.32 & 0 & 0 \\
\hline
\end{tabular}

Mann-Whitney $U$-test showed this difference was not statistically significant, $U=3932$ $p=0.735, r=0.025$. $p$-value equals $0.736524,(p(x \leq Z)=0.368262)$. This means that if we would reject $\mathrm{H} 0$, the chance of type I error (rejecting a correct $\mathrm{H} 0$ ) would be too high: 0.7365 
(73.65\%). The larger the $p$-value the more it supported H0. The statistic Z test, at baseline, was -0.336460 and was in the $95 \%$ critical value accepted range: [ $-1.9600: 1.9600]$. $\mathrm{U}=3932.00$, was in the $95 \%$ accepted range: [3365.5300: 0.01067 ]. The statistic $S^{\prime}$ equals 349.224. The observed standardized effect size, $Z / \sqrt{ }(n 1+n 2)$, was small: 0.025 , which indicates that the magnitude of the difference between the probability to choose a bigger value from the intervention group and the probability to choose a bigger value from the control group was small. The common language effect size, $U 1 /(n 1 n 2)$, was 0.49 . This was the probability that a random value from the intervention group was greater than a random value from the control group. At 3 months, the intervention group displayed lower values of $\mathrm{HbA1c}(\mathrm{Mdn}=7.25)$ than the control group $(M d n=7.65)$, but the difference was not statistically significant, $U=3512, p=0.123, r=0.115$. $p$-value equals 0.123723 , $(p(x \leq Z)=0.0618613)$. The test statistic $Z$ equals $-1.539335 ; U=3512.00$. The statistic $S^{\prime}$ was 349.177 , the statistic $Z$ test was -1.539335 and was in the $95 \%$ critical value accepted range: [-1.9600: 1.9600]. $U=3512.00$ and was in the $95 \%$ accepted range: [3365.6300: 0.01067]. The observed standardized effect size, $Z / \sqrt{ }(n 1+n 2)$, was small (0.11). The common language effect size, $U 1 /(n 1 n 2)$, was 0.43 . At 6 months, the intervention group had lower values of $\mathrm{HbA1c}(M d n=7.2)$ than the CG $(M d n=7.3)$. The difference was not statistically significant, $U=3757, p=0.401, r=0.063$. $p$-value equals 0.474786 , $(p(x \leq Z)=0.762607)$. The test statistic $Z$ equals $0.714714 ; U=4253.00$. The statistic $S^{\prime}$ equals 346.292. The observed standardized effect size, $Z / \sqrt{ }(n 1+n 2)$, was small (0.053). The common language effect size, $U 1 /(n 1 n 2)$, was 0.53 .

The PI at baseline for the intervention group had higher values $(M d n=80.5)$ than the control group $(M d n=70.5)$. These results showed this difference big enough to be statistically significant, $U=2642.5, p=0, r=0.301$. $p$-value equaled 0.0000527901 , $(p(x \leq Z)=0.999974)$ and the chance of type1 error was small: $0.00005279(0.0053 \%)$. The statistic $Z$ test equaled 4.042918 was not in the $95 \%$ critical value accepted range: [-1.9600: 1.9600]. $U=2642.5$ was not in the 95\% accepted range: [3367.9000: 0.01067]. The statistic $S^{\prime}$ equals 348.016. The observed standardized effect size, $Z / \sqrt{ }(n 1+n 2)$, was medium (0.30). The common language effect size, $\mathrm{U} 1 /(n 1 n 2)$, was 0.67 . At three months, the intervention group had lower values of PI $(M d n=15.5)$ compared to the control group $(M d n=70)$, and the difference was statistically significant, $U=57.5, p=0, r=0.852$. $p$-value equals 0.00000, $(p(x \leq Z)=0.00000)$. The test statistic $Z$ equaled $-11.427513 ; U=57.50$. The statistic $S^{\prime}$ equaled 349.332. At six months of follow up the difference of PI between the groups ( $M d n=12$ for IG and $M d n=69$ for CG respectively) was statistically significant, $U=15, p=0, r=0.861$. $p$-value equals 0.00000, $(p(x \leq Z)=0.00000)$. The test statistic $Z$ equaled $-11.548199 ; U=15.00$. The statistic $S^{\prime}$ equaled 349.362. The observed standardized effect size, $Z / \sqrt{ }(n 1+n 2)$, was large (0.86). The common language effect size, $U 1 /(n 1 n 2)$, was 0.0019. At baseline, also the difference of GI between the groups was statistically significant, $U=3330.5, p=0.039, r=0.154$. Specifically, the IG had higher values $(M d n=67)$ than the control group $(M d n=65)$. $p$-value equaled 0.0377597, $(p(x \leq Z)=0.981120)$. This means that the chance of type1 error was small: 0.03776 (3.78\%). The test statistic $Z$ equaled 2.077453 and was not in the $95 \%$ critical value accepted range: [-1.9600: 1.9600]. $U=4776.00$ was not in the $95 \%$ accepted range: [3365.5300: 0.01067 ]. The statistic $S^{\prime}$ equaled 349.226. The observed standardized effect size, $Z / \sqrt{ }(n 1+n 2)$, was small $(0.15)$. The common language effect size, $U 1 /(n 1 n 2)$, was 0.59 . At 3 months, the intervention group showed lower values of GI $(M d n=12.5)$ in comparison with the control group $(M d n=65)$. The difference was statistically significant, $U=70, p=0, \mathrm{r}=0.849$. $p$-value equaled 0.00000, $(p(x \leq Z)=0.00000)$. The test statistic $Z$ equaled $-11.38 ; U=70$. The statistic $S^{\prime}$ equaled 349.392. The observed standardized effect size, $Z / \sqrt{ }(n 1+n 2)$, was large (0.85). The common language effect size, $U 1 /(n 1 n 2)$, was 0.0086 . At 6 months, data showed that the GI values were lower in the intervention group $(M d n=10)$ than the control group $(M d n=64.5)$. Mann-Whitney $U$-test showed this difference was statistically significant, $U=33, p=0$, $r=0.857$. $p$-value equaled $0.00000,(p(x \leq Z)=0.00000)$. This means that the chance of type1 error was small: $0.000(0.0 \%)$. The smaller the $p$-value the more it supported 
H1. The test statistic $Z$ equaled $-11.49 ; \quad U=33$. The statistic $S^{\prime}$ equaled 349.322. The observed standardized effect size, $Z / \sqrt{ }(n 1+n 2)$, was large (0.86). The common language effect size, $U 1 /(n 1 n 2)$, was 0.0041 . The PD value at baseline was higher for IG $(M d n=4.85)$ than the CG $(M d n=4.5)$. This difference was statistically significant, $U=2885, p=0.001$, $r=0.249$. At 3 months, IG group revealed lower values $(M d n=2.9)$ than the control group $(M d n=4.5)$. The difference was statistically significant, $U=42.5, p=0, r=0.855$. Finally, at six months, the IG exhibited decreased values of PD $(M d n=2.86)$ than the CG group $(M d n=4.605)$, showing a statistically significant difference, $U=2, p=0, r=0.864$. The CAL parameter, at baseline, was higher for IG $(M d n=5.3)$ than the CG $(\mathrm{Mdn}=4.8)$. This difference indicated a statistically significant difference, $U=2625, p=0, r=0.305$. At the second timeline ( 3 months), the IG group presented lower values $(M d n=4.1)$ than the control group $(M d n=4.8)$. This difference was statistically significant, $U=1307.5, p=0$, $r=0.585$. The CAL index at 6 months had lower values $(M d n=4)$ than the CAL for CG $(M d n=5)$, establishing a statistically significant differences between groups, $U=948, p=0$, $r=0.662$. The CRP at baseline had higher concentration $(M d n=2.3)$ for the intervention group compared to the control group $(M d n=2.145)$, but the magnitude of the difference was not statistically significant, $U=4480.00, p=0.222, r=0.091$. The test statistic $Z$ equaled 1.2; $U=44.8$. The statistic $S^{\prime}$ equaled 349.437. The observed standardized effect size, $\mathrm{Z} / \sqrt{ }(\mathrm{n} 1+\mathrm{n} 2)$, was small (0.092). The common language effect size, $U 1 /(n 1 n 2)$, was 0.55 . At 3 months, the difference between the groups was big enough to be statistically significant. $p$-value equaled $0.0000467009,(p(x \leq Z)=0.0000233504)$. This means that the chance of a type1 error was small: $0.00004670(0.0047 \%)$. The test statistic Z equaled -4.071552 and was not in the $95 \%$ critical value accepted range: $[-1.9600: 1.9600]$. $U=2627.00$ and was not in the $95 \%$ accepted range: [3365.2400: 0.01067]. The statistic $S^{\prime}$ equaled 349.375. At 6 months, the control group had higher values $(M d n=2.33)$ than the intervention group $(M d n=1.32)$. This difference was statistically significant, $U=1839.5, p=0, r=0.472$. $p$-value equaled $2.52750 \times 10^{-10},\left(p(\mathrm{x} \leq \mathrm{Z})=1.26375 \times 10^{-10}\right)$. This means that the chance of type1 error (rejecting a correct $\left.\mathrm{H}_{0}\right)$ was small: $2.527 \times 10^{-10}\left(2.5 \times 10^{-8 \%} \%\right.$ ). The test statistic $\mathrm{Z}$ equaled -6.325; $U=18.39$. The statistic $S^{\prime}$ equaled 349.391. The observed standardized effect size, $\mathrm{Z} / \sqrt{ }(n 1+n 2)$, was medium (0.47). The common language effect size, $U 1 /(n 1 n 2)$, was 0.23 .

\subsection{Difference of HbA1c Values Within the Intervention Group Over the 6 Months}

At baseline, the $\mathrm{HbA} 1 \mathrm{c}$ values of the intervention group were higher $(M d n=7.7)$ than the $\mathrm{HbA} 1 \mathrm{c}$ at 3 months $(\mathrm{Mdn}=7.25)$. Mann-Whitney $U$-test showed this difference was not statistically significant, $U=3429, p=0.075, r=0.133$, while the difference between $\mathrm{HbA1c}$ values at baseline $(M d n=7.7)$ and 6 months $(M d n=7.2)$ was statistically significant, $U=3174.5, p=0.012, r=0.187$. No statistically significant difference was revealed about the differences between the HbA1c values at 3 months $(M d n=7.25)$ and the HbA1c values at 6 months $(M d n=7.2), U=3844.5, p=0.556, r=0.044$.

\subsection{Difference of HbA1c Values Within the Control Group Over the 6 Months}

At baseline, the $\mathrm{HbA} 1 \mathrm{c}$ values of the control group were lower $(M d n=7.7)$ compared with the analysis at 3 months $(M d n=7.9)$, but this difference was not statistically significant, $U=3751.5, p=0.393, r=0.064$. At 6 months, the control group had lower values $(M d n=7.3)$ than the baseline $(M d n=7.7)$, showing a statistically significant difference $U=3149.5$, $p=0.01, r=0.192$. Finally, at 6 months, the control group had lower values $(M d n=7.3)$ than the 3 months evaluation $(M d n=7.3)$, showing a statistically significant difference, $U=3142$, $p=0.009, r=0.194$.

\subsection{Difference of CRP Values Within the Intervention Group Over the 6 Months}

At 3 months the IG registered lower values $(M d n=1.43)$ than the baseline $(M d n=2.12)$. This difference was statistically significant, $U=3209.5, p=0.016, r=0.179$. At 6 months, results show lower values $(M d n=1.32)$ than the baseline $(M d n=2.12)$. The difference was statistically significant, $U=2606.5, p=0, r=0.308$. The difference between 3 and 6 months 
was not statistically significant, $U=3460.5, p=0.092, r=0.126$, with $M d n=1.43$ at 3 months and $M d n=1.32$ at 6 months.

\subsection{Difference of CRP Values Within the Control Group Over the 6 Months}

At 3 months, the control group had higher values $(M d n=2.5)$ than the baseline $(M d n=2.12)$, but the difference was not statistically significant, $U=3492.5, p=0.111$, $r=0.119$. At 6 months, the CRP concentration had higher values than the baseline $(M d n=2.12)$, showing an $M d n$ of 2.33. This difference was not statistically significant, $U=3806, p=0.487, r=0.052$.

The difference between the value at 3 months and 6 months was not statistically significant, $U=3610.5, p=0.21, r=0.094$, with $M d n=2.33$ and $M d n=2.5$, respectively.

\subsection{Effect on $\mathrm{HbA1c}$}

A multiple linear regression analysis was performed at 3 and 6 months to examine whether the periodontal parameters significantly predicted $\mathrm{HbA} 1 \mathrm{c}$ in the intervention group. At 3 months analysis, the regression model indicated that the predictors explained 0.056 of the variance and a collective significant effect was not found. $F=014, p=0.96$, $\mathrm{R}^{2}=0.0068$. Since $p$-value $\geq \alpha(0.5)$, we accepted the $\mathrm{H}_{1}$. The adjusted $\mathrm{R}$ square equaled -0.0399332 . The coefficient of multiple correlations $(\mathrm{R})$ equaled 0.0824947 . It means that there was a very weak direct relationship between the predicted data $(\hat{y})$ and the observed data $(y)$. The individual predictors are shown in Table 7.

Table 7. The individual predictors.

\begin{tabular}{cccccc}
\hline 3 Months & $\begin{array}{c}\text { Unstandardized } \\
\text { Coefficients }\end{array}$ & $\begin{array}{c}\text { Standardized } \\
\text { Coefficients }\end{array}$ & & & \\
\hline Model & $\mathbf{B}$ & $\beta$ & $\begin{array}{c}\text { Standard } \\
\text { Error }\end{array}$ & $\mathbf{t}$ & $\mathbf{t}$-Value \\
\hline (Constant) & 13.9 & & 3.23 & 4.32 & 0 \\
\hline PI & -0.03 & -0.32 & 0.02 & -1.3 & 0.18 \\
\hline GI & 0.03 & 0.32 & 0.02 & 1.36 & 0.17 \\
\hline PD & 0.27 & 0.08 & 0.45 & 0.61 & 0.5 \\
\hline CAL & -1.24 & -0.21 & 0.74 & -1.66 & 0.1 \\
\hline
\end{tabular}

\subsection{Effect on CRP}

A multiple linear regression analysis was performed to examine whether the, periodontal indices and glycated hemoglobin variables significantly predicted CRP over 3 and 6 months. The regression model indicated that the predictors explained 0.03 of the variance and a collective significant effect was not found. $\mathrm{F}=0.522, p=0.759, \mathrm{R}^{2}=0.03$. The individual predictors result is shown in Table 8 .

Table 8. The individual predictors.

\begin{tabular}{cccccc}
\hline & $\begin{array}{c}\text { Unstandardized } \\
\text { Coefficients }\end{array}$ & $\begin{array}{c}\text { Standardized } \\
\text { Coefficients }\end{array}$ & & & \\
\hline Model & $\mathbf{B}$ & Beta & $\begin{array}{c}\text { Standard } \\
\text { error }\end{array}$ & $\mathbf{t}$ & $p$-Value \\
\hline (Constant) & 1.37 & & 1.01 & 1.348 & 0.181 \\
\hline $\mathrm{HbA} 1 \mathrm{c}$ & 0.01 & 0.01 & 0.07 & 0.16 & 0.873 \\
\hline $\mathrm{PI}$ & -0.006 & -0.05 & 0.05 & -0.125 & 0.901 \\
\hline $\mathrm{GI}$ & 0.02 & 0.21 & 0.05 & 0.455 & 0.651 \\
\hline $\mathrm{PD}$ & -0.08 & -0.05 & 0.1 & -0.468 & 0.641 \\
\hline $\mathrm{CAL}$ & 0.11 & 0.07 & 0.16 & 0.67 & 0.504 \\
\hline
\end{tabular}




\section{Discussion}

Diabetes is a complex metabolic disorder affecting the glucose status of the human body, characterized by impaired action, secretion of insulin or both, resulting in hyperglycemia $[12,13,17-19,21,22,34]$. Chronic hyperglycemia related to diabetes is associated with end organ failure. Majority of people with diabetes fall into two broad pathogenetic categories, type 1 or type 2 diabetes [23,35]. The treatment in chronic illness has a decisive role and function of the economy in improving the quality of living [24-27,35-37]. The treatment of a patient with diabetes requires consideration of key pathogenic characteristics, the duration of disease, the age of patient and the presence of secondary diagnoses for specific complications or comorbidities [38]. Priority in management diabetes is the regression of pathology, by reaching the euglycemia and controlling the metabolic alterations [5,39-42]. The role of inflammation is under intensive scrutiny with several clinical trials to have been completed while more are in development [43]. The effective management of diabetes by introduction of the insulin therapy has been able to modify the natural history of diabetes, but there is currently no evidence that they prevent the long-term sequelae [44-46]. Conversely, the prolonged disease has a detrimental effect on the organic system, leading to significant chronic complications [47]. As a consequence of the glycemic excursions, diabetes has the major complications in the vascular system [48-50]. The micro(retinopathy, nephropathy and neuropathy and periodontal disease) and macrovascular (coronary, peripheral and cerebral vasculopaty), progressive injury occurs in at least $76 \%$ of diabetic patients within 10 years follow up [13,44-46]. Previously studies reported the observation of characteristic microvascular changes in the periodontal tissues associated with diabetic complications [39,51-55].

Periodontitis is chronic infectious inflammatory disease characterized by the progressive destruction of the periodontal apparatus [25-28] depending on the complex relationship between a susceptible host, pathogenic bacteria and an environment propitious for disease progression. Clinical presentation will be the same as for any extent, varying from minor to highest gum's bleeding, swelling and pain. Dental plaque, an organized biofilm of microorganisms, is the essential noxa pathogena, which elicits the onset of gingival inflammation [29,30], establishing and maintaining the intimate host-pathogen association. It begins as low-grade, protracted response to oral pathogen colonization, characterized by prolonged activation of a large amount of mononuclear leukocytes (monocytes and lymphocytes) accompanying tissue damage due to the vicious cycle linking inflammation and the pathological process it accompanies. When the pathogen stimulus is not controlled it can trigger a systemic response that has been demonstrated to prolong the general inflammatory status. Evidence has consistently supported that induction of cytokines, chemokines and acute-phase reactants occur during periodontal infection and is completely dependent on disease persistence [31]. Increased levels of C-reactive protein (CRP) have been associated with periodontitis in systemically healthy subjects.

It is well known the biunivocal association between periodontal disease and diabetes and pathophysiological mechanism related to immune functioning but is an underrecognized clinical problem [39,52-57]. Non-surgical periodontal treatment is associated with the reduction of $0.4 \%$ glycate hemoglobin (HbA1c) approximately [10,58-60]. The concept of periodontitis as "the sixth complication of diabetes" has been popularized by Loe in 1993 [49], who firstly demonstrated that the prevalence of periodontal disease was three times higher among type II diabetic persons compared with the nondiabetic $[39,52,53]$. Severe periodontitis has been associated with poor controlled diabetic condition, confirming that the release of inflammatory mediators due to poor glycemic control is implicated in the pathogenesis of periodontitis $[5,23]$. The experimental association studies have increased our knowledge about the link about diabetes and periodontitis. Non-surgical periodontal treatment has been found to be beneficial in glycemic control depending on several factors $[26,49]$. Consistent with findings in the literature, our study examined the correlation between periodontitis and later improvement of glycated hemoglobin percentage after non-surgical periodontal treatment, and the reduction of systemic inflammation through 
the assessment of C-reactive protein concentration [32-35]. Since previous studies clearly showed that periodontal therapy is effective in reducing the HbA1c level $[16,20,32,33]$, we hypothesized that periodontal status may adversely affect diabetes. Thus, we suggest that periodontal treatment may improve metabolic control in type 2 diabetes. In terms of study limitations, long-term follow-up might have offered greater awareness. Natural history studies indicate that alteration of the $\mathrm{HbA} 1 \mathrm{c}$ level is determined by several factors. The hypothesis that periodontal treatment has a role in influencing rates $\mathrm{HbA} 1 \mathrm{c}$ level remains controversial. The results from this study did not completely clarify the potential role of periodontal therapy in the metabolic control of diabetic patients. The high proportion of patients who demonstrated $\mathrm{HbA1c}$ reduction over 6-months 2 years in both groups indicates that several factors contribute to fluctuations of glycated hemoglobin. Our study found no statistical differences between the periodontal treatment or not in the metabolic control of diabetic patients over 6 months. Both groups achieved similar fluctuations over 6 months. Specifically, periodontal indices were elevated both in the intervention and control group at baseline, but a strong correlation was not found with $\mathrm{HbA1c}$ level. The intervention group initially had a higher level of $\mathrm{HbA} 1 \mathrm{c}$ and, therefore, the treatment effect was more significant. It is a good result for periodontal treatment. About the CRP concentration, we aimed to assess the oscillation of concentration after the periodontal treatment, assuming that the periodontal status could be a predictor of its decrease.

It is generally accepted that inflammation cytokines like the C-reactive protein (CRP) are a determinant for the connection between diabetes and periodontitis [61]. A metaanalysis conducted by Teeuw et al. [62] showed a significant reduction of CRP level after the periodontal treatment, and Katagiri et al. [63] observed a strong relationship between the change of CRP and HbA1c concentration. Several large scale cross-sectional studies reported elevated levels of serum CRP in gingivitis and periodontitis [64-66]. The effectiveness of periodontal treatment on CRP levels was also investigated from several reports indicating that CRP was consistently elevated in periodontitis individuals $(>2.1 \mathrm{mg} / \mathrm{L})$ compared with healthy controls. Our results were consistent with previous funding, which reported that periodontal treatment determined a statistically significant decrease of the CRP plasma levels after 3 months. It has been documented that 3 months post treatment is a suitable interval for the primary evaluation of non-surgical periodontal treatment. Therefore, our data confirm that periodontal therapy could significantly reduce systemic inflammation by improvement of the periodontal status.

However, also our results show that the CRP value was plausibly elevated in patients with periodontitis and diabetes, but no statistically significant relationship between all the variables was found. While more is becoming known regarding the role of inflammatory pathways linking diabetes and periodontitis, there remain many open questions [11-13,17-19,21,22,54].

\section{Conclusions}

There is emerging evidence to support the existence of a two-way relationship between diabetes and periodontitis, with diabetes increasing the risk for periodontitis, and periodontal inflammation negatively affecting glycemic control $[39,59]$. The mechanisms that underpin the links between these two conditions are not completely understood, but involve aspects of immune functioning, neutrophil activity and cytokine biology. One of the main findings of our study was that poor glycemic control was related to severity of periodontitis [61] and that periodontal disease could increase the amount of plasma CRP [10,67-69]. Further studies are needed for insight into the molecular mechanisms underlying inflammation and to elaborate further on the physiological role of this phenomenon.

Author Contributions: Conceptualization, B.R.; methodology, B.R.; software, B.R. and E.F.; validation, B.R., E.F., M.C., S.S., M.D., I.C., E.Q., F.L. and A.G.; formal analysis, B.R. and E.F.; investigation, B.R. and E.F.; resources, B.R.; data curation, B.R., E.F. and. A.S.; writing-original draft preparation, B.R.; writing-review and editing, B.R., E.F., E.Q. and A.S.; visualization, I.C., M.C., A.G. and S.S.; 
supervision, B.R. and E.F.; project administration B.R. and A.S. All authors have read and agreed to the published version of the manuscript.

Funding: This research received no external funding.

Institutional Review Board Statement: The study was conducted according to the guidelines of the Declaration of Helsinki, and approved by the local Ethics Committee of Albania University, Tiran, Albania (Nr. 385 Prot.).

Informed Consent Statement: Informed consent was obtained from all subjects involved in the study.

Data Availability Statement: All data to support the findings of this study are available contacting the corresponding author upon request. The authors have annotated the entire data building process and empirical techniques described in the paper.

Conflicts of Interest: The authors declare no conflict of interest.

\section{References}

1. Khan, M.A.B.; Hashim, M.J.; King, J.K.; Govender, R.D.; Mustafa, H.; Al Kaabi, J. Epidemiology of Type 2 Diabetes-Global Burden of Disease and Forecasted Trends. J. Epidemiol. Glob. Health 2020, 10, 107-111. [CrossRef] [PubMed]

2. Albandar, J.M.; Susin, C.; Hughes, F.J. Manifestations of systemic diseases and conditions that affect the periodontal attachment apparatus: Case definitions and diagnostic considerations. J. Clin. Periodontol. 2018, 45, S171-S189. [CrossRef] [PubMed]

3. Hegde, R.; Awan, K.H. Effects of periodontal disease on systemic health. Dis. Mon. 2019, 65, 185-192. [CrossRef]

4. Yeo, B.K.; Lim, L.P.; Paquette, D.W.; Williams, R.C. Periodontal disease-The emergence of a risk for systemic conditions: Pre-term low birth weight. Ann. Acad Med. Singap. 2005, 34, 111-116.

5. Papapanou, P.N.; Sanz, M.; Buduneli, N.; Dietrich, T.; Feres, M.; Fine, D.H.; Flemmig, T.F.; Garcia, R.; Giannobile, W.V.; Graziani, F.; et al. Periodontitis: Consensus report of workgroup 2 of the 2017 World Workshop on the Classification of Periodontal and Peri-Implant Diseases and Conditions. J. Clin. Periodontol. 2018, 45, S162-S170. [CrossRef] [PubMed]

6. Herrera, D.; Retamal-Valdes, B.; Alonso, B.; Feres, M. Acute periodontal lesions (periodontal abscesses and necrotising periodontal diseases) and endo-periodontal lesions. J. Clin. Periodontol. 2018, 45, S78-S94. [CrossRef]

7. Fine, D.H.; Patil, A.G.; Loos, B.G. Classification and diagnosis of aggressive periodontitis. J. Clin. Periodontol. 2018, 45, S95-S111. [CrossRef] [PubMed]

8. Needleman, I.; Garcia, R.; Gkranias, N.; Kirkwood, K.L.; Kocher, T.; Iorio, A.D.; Moreno, F.; Petrie, A. Mean annual attachment, bone level, and tooth loss: A systematic review. J. Clin. Periodontol. 2018, 45, S112-S129. [CrossRef]

9. Billings, M.; Holtfreter, B.; Papapanou, P.N.; Mitnik, G.L.; Kocher, T.; Dye, B.A. Age-dependent distribution of periodontitis in two countries: Findings from NHANES 2009 to 2014 and SHIP-TREND 2008 to 2012. J. Clin. Periodontol. 2018, 45, S130-S148. [CrossRef]

10. Tonetti, M.S.; Greenwell, H.; Kornman, K.S. Staging and grading of periodontitis: Framework and proposal of a new classification and case definition. J. Clin. Periodontol. 2018, 45, S149-S161. [CrossRef] [PubMed]

11. Tonetti, M.S.; Sanz, M. Implementation of the New Classification of Periodontal Diseases: Decision-making Algorithms for Clinical Practice and Education. J. Clin. Periodontol. 2019, 46, 398-405. [CrossRef] [PubMed]

12. Quaglia, E.; Moscufo, L.; Corsalini, M.; Coscia, D.; Sportelli, P.; Cantatore, F.; De Rinaldis, C.; Rapone, B.; Carossa, M.; Carossa, S. Polyamide vs silk sutures in the healing of postextraction sockets: A split mouth study. Oral Implantol. 2018, 11, 115-120.

13. Rapone, B.; Corsalini, M.; Converti, I.; Loverro, M.T.; Gnoni, A.; Trerotoli, P.; Ferrara, E. Does Periodontal Inflammation Affect Type 1 Diabetes in Childhood and Adolescence? A Meta-Analysis. Front. Endocrinol. 2020, 11, 278. [CrossRef] [PubMed]

14. Nazir, M.; Al-Ansari, A.; Al-Khalifa, K.; Alhareky, M.; Gaffar, B.; Almas, K. Global Prevalence of Periodontal Disease and Lack of Its Surveillance. Sci. World J. 2020, 2020, 2146160. [CrossRef]

15. World Health Organization. Oral Health; World Health Organization: Geneva, Switzerland, 2018.

16. GBD 2017 Disease and Injury Incidence and Prevalence Collaborators. Global, regional, and national incidence, prevalence, and years lived with disability for 328 diseases and injuries for 195 countries, 1990-2016: A systematic analysis for the Global Burden of Disease Study 2016. Lancet 2017, 390, 1211-1259. [CrossRef]

17. Montemurro, N.; Perrini, P.; Rapone, B. Clinical Risk and Overall Survival in Patients with Diabetes Mellitus, Hyperglycemia and Glioblastoma Multiforme. A Review of the Current Literature. Int. J. Environ. Res. Public Health 2020, 17, 8501. [CrossRef]

18. Tsalamandris, S.; Antonopoulos, A.S.; Oikonomou, E.; Papamikroulis, G.A.; Vogiatzi, G.; Papaioannou, S.; Deftereos, S.; Tousoulis, D. The Role of Inflammation in Diabetes: Current Concepts and Future Perspectives. Eur. Cardiol. 2019, 14, 50-59. [CrossRef]

19. Donath, M.Y.; Shoelson, S.E. Type 2 diabetes as an inflammatory disease. Nat. Rev. Immunol. 2011, 11, 98-107. [CrossRef] [PubMed]

20. Consensus Report: Chronic Periodontitis International Workshop for a Classification of Periodontal Diseases and Conditions. Ann. Periodontol. 1999, 4, 38.

21. Chee, B.; Park, B.; Bartold, P.M. Periodontitis and type II diabetes: A two-way relationship. Int. J. Evid. Based Healthc. 2013, 11, 317-329. [CrossRef] 
22. Wu, C.Z.; Yuan, Y.H.; Liu, H.H.; Li, S.S.; Zhang, B.W.; Chen, W.; An, Z.J.; Chen, S.Y.; Wu, Y.Z.; Han, B.; et al. Epidemiologic relationship between periodontitis and type 2 diabetes mellitus. BMC Oral Health 2020, 20, 204. [CrossRef]

23. Rapone, B.; Ferrara, E.; Corsalini, M.; Converti, I.; Grassi, F.R.; Santacroce, L.; Topi, S.; Gnoni, A.; Scacco, S.; Scarano, A.; et al. The Effect of Gaseous Ozone Therapy in Conjunction with Periodontal Treatment on Glycated Hemoglobin Level in Subjects with Type 2 Diabetes Mellitus: An Unmasked Randomized Controlled Trial. Int. J. Environ. Res. Public Health 2020, $17,54675$. [CrossRef] [PubMed]

24. Kassebaum, N.J.; Bernabe, E.; Dahiya, M.; Bhandari, B.; Murray, C.J.; Marcenes, W. Global burden of severe periodontitis in 1990-2010: A systematic review and meta-regression. J. Dent. Res. 2014, 93, 1045-1053. [CrossRef] [PubMed]

25. Bascones-Martinez, A.; Munoz-Corcuera, M.; Bascones-Ilundain, J. Diabetes and periodontitis: A bidirectional relationship. Med. Clin. 2015, 145, 31-35. [CrossRef]

26. Baynes, H.W.; Mideksa, S.; Ambachew, S. The role of polyunsaturated fatty acids (n-3 PUFAs) on the pancreatic $\beta$-cells and insulin action. Adipocyte 2018, 14, 1-7. [CrossRef]

27. Oh, Y.S.; Bae, G.D.; Baek, D.J.; Park, E.-Y.; Jun, H.-S. Fatty Acid-Induced Lipotoxicity in Pancreatic Beta-Cells During Development of Type 2 Diabetes. Front. Endocrinol. 2018, 9, 384. [CrossRef] [PubMed]

28. Lumeng, C.N.; Bodzin, J.L.; Saltiel, A.R. Obesity induces a phenotypic switch in adipose tissue macrophage polarization. J. Clin. Investig. 2007, 117, 175-184. [CrossRef]

29. Vlassara, H.; Uribarri, J. Advanced glycation end products (AGE) and diabetes: Cause, effect, or both? Curr. Diabetes Rep. 2014, 14, 453. [CrossRef]

30. Hameed, I.; Masoodi, S.R.; Mir, S.A.; Nabi, M.; Ghazanfar, K.; Ganai, A.B. Type 2 diabetes mellitus: From a metabolic disorder to an inflammatory condition. World J. Diabetes 2015, 6, 598-612. [CrossRef]

31. Kay, A.M.; LaShan Simpson, C.; Stewart, J.A., Jr. The Role of AGE/RAGE Signaling in Diabetes-Mediated Vascular Calcification. J. Diabetes Res. 2016, 2016, 6809703. [CrossRef]

32. Van Dyke, T.E. Inflammation and periodontal diseases: A reappraisal. J. Periodontol. 2008, 79, 1501-1502. [CrossRef]

33. Cekici, A.; Kantarci, A.; Hasturk, H.; Van Dyke, T.E. Inflammatory and immune pathways in the pathogenesis of periodontal disease. Periodontol. 2000 2014, 64, 57-80. [CrossRef] [PubMed]

34. Garlet, G.P. Destructive and Protective Roles of Cytokines in Periodontitis: A Re-appraisal from Host Defense and Tissue Destruction Viewpoints. J. Dent. Res. 2010, 89, 1349-1363. [CrossRef]

35. Dutzan, N.; Kajikawa, T.; Abusleme, L.; Greenwell-Wild, T.; Zuazo, C.E.; Ikeuchi, T.; Brenchley, L.; Abe, T.; Hurabielle, C.; Martin, D.; et al. A dysbiotic microbiome triggers Th17 cells to mediate oral mucosal immunopathology in mice and humans. Sci. Transl. Med. 2018, 10, eaat0797. [CrossRef] [PubMed]

36. Chen, C.; Hemme, C.; Beleno, J.; Shi, Z.J.; Ning, D.; Qin, Y.; Tu, Q.; Jorgensen, M.; He, Z.; Wu, L.; et al. Oral microbiota of periodontal health and disease and their changes after nonsurgical periodontal therapy. ISME J. 2018, 12, 1210-1224. [CrossRef] [PubMed]

37. Marsh, P.D. Microbial ecology of dental plaque and its significance in health and disease. Adv. Dent. Res. 1994, 8, 263-271. [CrossRef] [PubMed]

38. Sima, C.; Cheng, Q.; Rautava, J.; Levesque, C.; Sherman, P.; Glogauer, M. Identification of quantitative trait loci influencing inflammation-mediated alveolar bone loss: Insights into polygenic inheritance of host-biofilm disequilibria in periodontitis. J. Periodont. Res. 2016, 51, 237-249. [CrossRef]

39. Gani, D.K.; Lakshmi, D.; Krishnan, R.; Emmadi, P. Evaluation of C-reactive protein and interleukin-6 in the peripheral blood of patients with chronic periodontitis. J. Indian Soc. Periodontol. 2009, 13, 69-74. [CrossRef] [PubMed]

40. Ide, M.; McPartlin, D.; Coward, P.Y.; Crook, M.; Lumb, P.; Wilson, R.F. Effect of treatment of chronic periodontitis on levels of serum markers of acute-phase inflammatory and vascular responses. J. Clin. Periodontol. 2003, 30, 334-340. [CrossRef]

41. Gupta, S.; Suri, P.; Patil, P.B.; Rajguru, J.P.; Gupta, P.; Patel, N. Comparative evaluation of role of hs C-reactive protein as a diagnostic marker in chronic periodontitis patients. J. Fam. Med. Prim. Care 2020, 9, 1340-1347. [CrossRef] [PubMed]

42. Rapone, B.; Ferrara, E.; Santacroce, L.; Topi, S.; Converti, I.; Gnoni, A.; Scarano, A.; Scacco, S. Gingival crevicular blood as a potential screening tool: A cross sectional comparative study. Int. J. Environ. Res. Public Health 2020, 17, 7356. [CrossRef] [PubMed]

43. Grover, H.S.; Luthra, S. Molecular mechanisms involved in the bidirectional relationship between diabetes mellitus and periodontal disease. J. Indian Soc. Periodontol. 2013, 17, 292-301. [PubMed]

44. Walmsley, A.D.; Laird, W.R.; Williams, A.R. Dental plaque removal by cavitational activity during ultrasonic scaling. J. Clin. Periodontol. 1988, 15, 539-543. [CrossRef]

45. Russell, A.L. A system for classification and scoring for prevalence surveys of periodontal disease. J. Dent. Res. 1956, 35, 350-359. [CrossRef]

46. Boutron, I.; Moher, D.; Altman, D.G.; Schulz, K.F.; Ravaud, P. Extending the CONSORT statement to randomized trials of nonpharmacologic treatment: Explanation and elaboration. Ann. Intern. Med. 2008, 148, 295-309. [CrossRef]

47. Caton, J.G.; Armitage, G.; Berglundh, T.; Chapple, I.L.C.; Jepsen, S.; Kornman, K.S.; Mealey, B.L.; Papapanou, P.N.; Mariano Sanz, M.; Tonetti, M.S. A new classification scheme for periodontal and peri-implant diseases and conditions-Introduction and key changes from the 1999 classification. J. Clin. Periodontol. 2018, 45, S1-S8. [CrossRef] [PubMed] 
48. Javed, F.; Klingspor, L.; Sundin, U.; Altamash, M.; Klinge, B.; Engström, P.E. Periodontal conditions, oral Candida albicans and salivary proteins in type 2 diabetic subjects with emphasis on gender. BMC Oral Health 2009, 9, 12. [CrossRef]

49. Löe, H. Periodontal disease. The sixth complication of diabetes mellitus. Diabetes Care 1993, 16, 329-334. [CrossRef] [PubMed]

50. Urzúa, B.; Hermosilla, G.; Gamonal, J.; Morales-Bozo, I.; Canals, M.; Barahona, S.; Cóccola, C.; Cifuentes, V. Yeast diversity in the oral microbiota of subjects with periodontitis: Candida albicans and Candida dubliniensis colonize the periodontal pockets. Med. Mycol. 2008, 46, 783-793. [CrossRef]

51. Scarano, A.; Barros, R.R.; Iezzi, G.; Piattelli, A.; Novaes, A.B., Jr. Acellular dermal matrix graft for gingival augmentation: A preliminary clinical, histologic, and ultrastructural evaluation. J. Periodontol. 2009, 80, 253-259. [CrossRef] [PubMed]

52. Casanova, L.; Hughes, F.; Preshaw, P. Diabetes and periodontal disease: A two-way relationship. Br. Dent. J. 2014, $217,433-437$. [CrossRef]

53. Jowett, A.K.; Orr, M.T.; Rawlinson, A.; Robinson, P.G. Psychosocial impact of periodontal disease and its treatment with $24 \mathrm{~h}$ root surface debridement. J. Clin. Periodontol 2009, 36, 413-418. [CrossRef] [PubMed]

54. Slade, G.D.; Ghezzi, E.M.; Heiss, G.; Beck, J.D.; Riche, E.; Offenbacher, S. Relationship between periodontal disease and C-reactive protein among adults in the Atherosclerosis Risk in Communities study. Arch. Intern. Med. 2003, 163, 1172-1179. [CrossRef] [PubMed]

55. Stratton, I.M.; Adler, A.I.; Neil, H.A.; Matthews, D.R.; Manley, S.E.; Cull, C.A.; Hadden, D.; Turner, R.C.; Holman, R.R. Association of glycaemia with macrovascular and microvascular complications of type 2 diabetes (UKPDS 35): Prospective observational study. BMJ 2000, 321, 405-412. [CrossRef]

56. Taylor, J.J.; Preshaw, P.M.; Lalla, E. A review of the evidence for pathogenic mechanisms that may link periodontitis and diabetes. J. Clin. Periodontol. 2013, 40, S113-S134. [CrossRef] [PubMed]

57. Borrell, L.N.; Kunzel, C.; Lamster, I.; Lalla, E. Diabetes in the dental office: Using NHANES III to estimate the probability of undiagnosed disease. J. Periodontal Res. 2007, 42, 559-565. [CrossRef]

58. Lorusso, F.; Postiglione, F.; Delvecchio, M.; Rapone, B.; Scarano, A. The impact of diabetes on implant oral rehabilitations: A bibliometric study and literature review. Acta Med. Mediterr. 2020, 36, 3333.

59. Katz, J. Elevated blood glucose levels in patients with severe periodontal disease. J. Clin. Periodontol. 2001, 28, 710-712. [CrossRef]

60. Yilmaz, D.; Caglayan, F.; Buber, E.; Könönen, E.; Aksoy, Y.; Gursoy, U.K.; Guncu, G.N. Gingival crevicular fluid levels of human beta-defensin-1 in type 2 diabetes mellitus and periodontitis. Clin. Oral Investig. 2018, 22, 2135-2140. [CrossRef]

61. Mattila, K.; Vesanen, M.; Valtonen, V.; Nieminen, M.; Palosuo, T.; Rasi, V.; Asikainen, S. Effect of treating periodontitis on C-reactive protein levels: A pilot study. BMC Infect. Dis. 2002, 2, 30. [CrossRef] [PubMed]

62. Teeuw, W.J.; Gerdes, V.E.; Loos, B.G. Effect of periodontal treatment on glycemic control of diabetic patients: A systematic review and meta-analysis. Diabetes Care 2010, 33, 421-427. [CrossRef] [PubMed]

63. Katagiri, S.; Nitta, H.; Nagasawa, T.; Uchimura, I.; Izumiyama, H.; Inagaki, K.; Kikuchi, T.; Noguchi, T.; Kanazawa, M.; Matsuo, A.; et al. Multi-center intervention study on glycohemoglobin (HbA1c) and serum, high-sensitivity CRP (hs-CRP) after local anti-infectious periodontal treatment in type 2 diabetic patients with periodontal disease. Diabetes Res. Clin. Pract. 2009, 83, 308-315. [CrossRef]

64. Buhlin, K.; Gustafsson, A.; Pockley, A.G.; Frostegård, J.; Klinge, B. Risk factors for cardiovascular disease in patients with periodontitis. Eur. Heart J. 2003, 24, 2099-2107. [CrossRef] [PubMed]

65. Ebersole, J.L.; Machen, R.L.; Steffen, M.J.; Willmann, D.E. Systemic acute-phase reactants, C-reactive protein and haptoglobin, in adult periodontitis. Clin. Exp. Immunol. 1997, 107, 347-352. [CrossRef]

66. Liu, J.; Wu, Y.F.; Ding, Y.; Ge, S.; Rao, L.; Tang, H. Serum C-reactive protein levels and lipid profiles concentrations in moderate to severe periodontitis and coronary heart disease: A comparative study. Zhonghua Kou Qiang Yi Xue Za Zhi 2009, 44, 150-154. [PubMed]

67. Bansal, T.; Pandey, A.; Asthana, A.K. C-Reactive Protein (CRP) and its Association with Periodontal Disease: A Brief Review. J. Clin. Diagn Res. 2014, 8, ZE21-ZE24. [PubMed]

68. Persson, G.R.; Pettersson, T.; Ohlsson, O.; Renvert, S. High-sensitivity serum C-reactive protein levels in subjects with or without myocardial infarction or periodontitis. J. Clin. Periodontol. 2005, 32, 219-224. [CrossRef]

69. Salzberg, T.N.; Overstreet, B.T.; Rogers, J.D.; Califano, J.V.; Best, A.M.; Schenkein, H.A. C-reactive protein levels in patients with aggressive periodontitis. J. Periodontol. 2006, 77, 933-939. [CrossRef] 